Published in final edited form as:

Arthritis Rheumatol. 2017 January ; 69(1): 9-21. doi:10.1002/art.39842.

\title{
Metabolic Regulation of Inflammation in Osteoarthritis
}

\author{
Francis Berenbaum, M.D., Ph.D. ${ }^{1}$, Timothy M. Griffin, Ph.D. ${ }^{2}$, and Ru Liu-Bryan, Ph.D. ${ }^{3}$ \\ ${ }^{1}$ Sorbonnes Universités, UPMC University Paris 06, INSERM, APHP hôpital Saint-Antoine, \\ Centre de Recherche Saint-Antoine (CRSA), DHU i2B, F-75012Paris, France
}

${ }^{2}$ Aging and Metabolism Research Program, Oklahoma Medical Research Foundation, Depts. of Biochemistry and Molecular Biology, Physiology, and Geriatric Medicine, University of Oklahoma Health Sciences Center, Oklahoma City, OK, USA

3VA San Diego Healthcare System, Dept. of Medicine, University of California San Diego, San Diego, California, USA

\section{Keywords}

Metabolic Syndrome; Obesity; AMPK; Sirtuins; Adipokines; Energy metabolism

\section{Introduction}

Osteoarthritis (OA) has long been considered the unique consequence of a tear and wear process leading to cartilage degradation. Indeed, it is true that an excessive mechanical stress on any joint leads to cartilage loss, with the production of osteophytes being considered a reactive process of the bone to protect and stabilize the altered joint (1). This initial paradigm has been slowly but deeply modified in the past 20 years due to critical discoveries (2). First, the enzymes involved in cartilage degradation have been identified as belonging to metalloproteinases and ADAMTS families, with pro-inflammatory cytokines regulating all of these enzymes. It was the first time that the pathophysiology of OA was associated with a role of soluble mediators better known in the pathophysiology of many other classical inflammatory diseases. Second, later on, whereas synovitis was considered as pathognomonic of RA, some groups demonstrated that a mild to severe synovitis reaction was frequently present in $\mathrm{OA}$, its intensity being correlated to prognosis $(3,4)$. Third, the role of obesity in OA shifted from an exclusive deleterious mechanical effect on load-bearing joints to its capacity to play a role in hand OA too. Indeed, epidemiological studies demonstrated that obese patients have a 2-fold increase in hand OA compared to a non-obese population (5). The interpretation of these unexpected results has been related to a well-

Contact information: Pr Francis BERENBAUM, Head of the Department of Rheumatology, Team leader "Age-related joint diseases and metabolism", INSERM UMR-S938, Faculty of Medicine Pierre \& Marie Curie Paris VI, Saint-Antoine hospital, AP-HP, 184 rue du faubourg Saint-Antoine, 75012 PARIS, France, tel. +33 1492825 20; Fax. +33 1492825 13, francis.berenbaum@ aphp.fr; Timothy M. Griffin, Ph.D., Associate Member, Aging and Metabolism Research Program, Oklahoma Medical Research Foundation, MS 21, 825 NE $13^{\text {th }}$ St, Oklahoma City, OK 73104 USA, Phone: (405) 271-7579; Fax: (405) 271-1437, Tim-Griffin@ omrf.org; Ru Liu-Bryan, PhD, VA San Diego Healthcare System, 111K, 3350 La Jolla Village Drive, San Diego, CA 92161 USA, ruliu@ucsd.edu. Author Contributions All authors were involved in drafting the article and revising it critically for important intellectual content, and all authors approved the final version to be published. 
known systemic release of pro-inflammatory cytokines primarily by abdominal adipose tissue (called adipocytokines or adipokines), which cause a low-grade inflammatory state involved in damage to many peripheral tissues, including joint tissues (2). More recently, the intra-articular fat pads, adipose tissue present inside some joints, have been considered as a new potential source of adipokines (6). All these steps demonstrating the role of inflammation in OA opened the door to a novel and exciting area of research trying to understand the molecular interactions between local articular tissues/cells and distant organs/ tissues and how these metabolic processes are disturbed in OA.

\section{Epidemiological and prospective clinical studies linking metabolic syndrome and $O A$}

Puenpatum et al. were the first to suggest that, on top of obesity, the metabolic syndrome (MetS) (defined as the association of components that independently increase the risk of cardiovascular events: abdominal adiposity, diabetes or insulin resistance, high cholesterol, and high blood pressure) could be an independent risk factor for OA (7). They found in the NHANES III cohort that $59 \%$ of OA patients had MetS compared to $23 \%$ in the general population. Furthermore, they calculated that having OA at 44 years old increases 5.26-fold the risk of having a concomitant MetS, suggesting that the presence of knee OA should inform the practitioner on a need to screen for MetS. Then, other cross-sectional studies confirmed this association (8-12), even if obesity could sometimes be a strong confounding factor longitudinally (13). Nevertheless, the presence of MetS is also associated with hand OA. Taking advantage of an increased prevalence of metabolic syndrome in HIV patients, Tomi et al. looked at the prevalence of hand OA in sex and age-matched HIV patients according to their metabolic status. Interestingly, hand OA prevalence was higher for those with MetS than those without it ( $64.7 \%$ vs $46.3 \%, \mathrm{p}=0.002)$ and the severity was greater (14). In the Netherlands Epidemiology of Obesity population cohort, hand OA was associated with MetS, adjusted for weight (OR 1.46 (95\% CI 1.06 to 2.02)) (15).

But a breakthrough in this field comes from the recent publication of several prospective cohorts showing that obese patients with MetS have an increased risk of incidence and severity of knee and hand OA (Table 1) (13,16-21). Based on a sample of 482 women with knee OA, the prevalence of knee OA in obese women with less than 2 cardiometabolic parameters (low levels of high-density lipoprotein cholesterol; elevated levels of low-density lipoprotein cholesterol, triglycerides, blood pressure, C-reactive protein, waist:hip ratio, or glucose; or diabetes mellitus) was $12.8 \%$ compared to $23.2 \%$ in obese women with more or equal to 2 cardiometabolic parameters (16).

Interestingly, some of these studies show that incidence and severity were positively correlated to the number of cardiometabolic parameters. In a multivariate analysis based on a cohort of 1384 Japanese individuals followed 3 years (ROAD cohort), the incidence of knee OA significantly increased according to the number of MetS components (OR vs no parameters: one parameters, 2.33; two components, 2.82; $\geq$ three parameters, 9.83) (17). Similarly, progression of knee OA significantly increased according to the number of parameters present (OR vs no component: one component, 1.38; two components, 2.29; $\geq$ 
three components: 2.80). In a large Australian population cohort followed during 2003-2007 (the Melbourne Collaborative Cohort Study), 660 patients had a total knee replacement (TKR) for OA (18). The accumulation of MetS components was associated with TKR, independently of BMI: one component, OR 2.12 (1.15-3.91); two components, 2.92 (1.605.33) and three or more components, 3.09 (1.68-5.69).

However, the weight of each of these factors for increasing OA risk remains largely unknown. Suffering from diabetes mellitus is associated with an independent increase of incident, prevalent and severe OA, although discrepancies exist in the literature (19) (review in (22)). Recent studies have shown an increased risk of knee or hand OA in hypertensive and/or atherosclerotic patients, giving strength to the hypothesis that an abnormal perfusion of the subchondral bone due to atherosclerosis could participate into the OA process $(18,21,23)$. Interestingly, this hypothesis fits with a recent study showing an association of serum cholesterol and triglyceride levels with the incidence of bone marrow lesions on knee MRI at 2 years in an asymptomatic middle-aged women population (20). Moreover, in a population of 809 OA patients, hypercholesterolemia (OR 1.61; 95\% CI 1.06-2.47) and high serum cholesterol levels (3rd versus 1st tertile: OR 1.73; 95\% CI 1.02-2.92) were independently associated with generalized OA (24). Such an independent association has also been shown in hand OA (25).

Some groups looked at the prognostic value of plasma concentration of adipokines in OA cohorts. An association between leptin levels (but not adiponectin) and knee OA occurrence and progression was demonstrated in a 5-year cohort but this association disappeared after adjustment for BMI (26). In the CHECK cohort, there is a weak association between resistin levels (but not leptin) and disease progression (27). Finally, hand OA patients with high adiponectin levels (but not leptin nor resistin) had a decrease disease progression compared to normal/low levels in a Dutch cohort (28).

Taken together, these epidemiological studies show clear associations between OA, the MetS, and its components, with some of them being clearly independent of the overload effect of obesity (Figure 1). However, there is a high heterogeneity in the design of all these cross-sectional and longitudinal epidemiological studies (definition of the MetS, gender selection, record of medication, etc.), which prevents a definitive conclusion on the real impact of the MetS on knee OA initiation and progression. Recent experimental in vitro and animal studies have helped to begin deciphering the potential roles of each of these factors in the initiation and progression of OA.

\section{Perspectives on the role of metabolic inflammation in OA from obese animal models}

Beginning in the 1940s, Drs. Martin and Ruth Silberberg studied the role of increased dietary fat on the development of OA in mice. They showed that supplementing rodent chow with lard (30\% by weight) increased the incidence of knee OA in C57BL mice by 2 -fold (29). Recent studies replicated these early observations in both spontaneous and posttraumatic models of OA (Table 2), focusing primarily on changes in inflammatory cytokines and adipokines as mediators of the increase in OA pathology (30-34). In spontaneous 
models, knee OA severity was positively correlated with total body fat, and numerous cytokines and adipokines were also elevated with the percentage of body fat (30-32). Statistically adjusting for adiposity using multivariable modeling negated most of the associations between systemic inflammatory mediators and knee OA, except for leptin and adiponectin $(30,31)$.

These findings are notable since both leptin and adiponectin are implicated in OA pathogenesis $(26,28)$. They are also of interest because mice with loss of function mutations in the leptin gene or the leptin receptor gene are protected from developing knee OA despite an extreme obesity phenotype, with body weights in excess of 80 grams and body fat levels $>50 \%$ (35). Mice with impaired leptin signaling become obese primarily by hyperphagia, and in the study by Griffin and colleagues (35), leptin deficient mice were fed a normal chow-based diet. Increasing body weight by chemically inducing hyperphagia in mice fed a normal chow diet also does not increase knee OA [reviewed in (36)]. This finding may be explained by the anti-inflammatory and anti-oxidative actions of aurothioglucose, the chemical agent used to induce hyperphagy. However, it also raises the possibility that an increase in dietary fat or the composition of fat itself contribute to OA pathogenesis.

Mice fed high-fat lard diets supplemented with polyunsaturated fatty acids (PUFAs) or diets composed of vegetable oils (e.g., cottonseed oil) develop less severe knee OA (36). Fatty acids are well known to modulate inflammation positively or negatively, and recent studies have tested the effect of different types of dietary fatty acids on inflammation in rodent models of idiopathic and post-traumatic OA. Two central classes of lipid mediators of inflammation are omega-6 (n-6) and omega-3 (n-3) PUFAs. n-6 PUFAs, such as arachidonic acid, are precursors of pro-inflammatory eicosanoids, including prostaglandins, thromboxanes, and leukotrienes. Conversely, n-3 PUFAs, such as eicosapentaenoic and docosahexaenoic acids, inhibit inflammation and accelerate its resolution. Obesogenic diets of middle and high-income countries, commonly referred to as Western Diets, contain a high ratio of n-6:n-3 PUFAs.

Two recent studies in mice have shown that decreasing the ratio of n-6:n-3 PUFAs, either by diet or genetically through the introduction of the fat- 1 transgene that endogenously converts n-6 to n-3 PUFAs, reduces the development of post-traumatic knee OA $(37,38)$. This reduction was associated with a decrease in serum pro-inflammatory cytokines and adipokines (e.g., IL-1 $\beta$, TNF, leptin, and resistin), joint synovitis, synovial macrophage infiltration, and heterotrophic joint ossifications. Intriguingly, wound healing in an ear-punch model was also improved by reducing the ratio of n-6:n:3 PUFAs (38). In contrast, the development of early-stage idiopathic knee OA in 1 year-old fat- 1 transgenic mice was not reduced compared to control littermates despite lower serum IL-6 and TNF levels (39). These studies suggest that the ratio of n-6:n-3 PUFAs has the greatest impact on OA progression under conditions of more acute activation of cellular and humoral immune responses, such as following tissue damage or joint trauma. It is not yet clear how n-6 and n-3 PUFAs regulate joint inflammation and repair. There is evidence that the ratio of n-6:n-3 PUFAs directly modulate cytokine-induced catabolic responses in joint connective tissues, such as cartilage (40); however, the effect likely involves heterogeneous cell populations involved in the regulation of wound healing and resolution of inflammation. A recent 
randomized clinical trial of fish oil supplementation in knee OA patients showed improvement in OA-related pain and function at 2 years, albeit without altering cartilage loss (41), suggesting that n-3 PUFAs may also reduce inflammation by improving physiologic joint use and function.

Another way in which high-fat diets may stimulate joint inflammation and OA is through activation of innate immune pathways. Obesogenic high-fat diets and alcohol consumption impair the gut mucosal barrier, resulting in increased intestinal permeability and elevated circulating levels of lipopolysaccharide. In addition, long-chain saturated fatty acids have also been implicated in promoting low-grade inflammation through activation of the Tolllike receptor (TLR) pathway, specifically TLR4. Mice lacking functional lipopolysaccharide receptor CD14 and TLR4 are partially protected from high-fat diet induced inflammation and related metabolic impairments, such as insulin resistance. Two recent animal studies support a model of systemic lipopolysaccharide inflammation in OA $(42,43)$. However, this work is at an early stage, and there are many questions about how TLR4 or lipopolysaccharide may mediate inflammation in OA (44).

A growing body of work has implicated dyslipidemia in innate immune pathway activation and OA pathophysiology. Activated synovial macrophages are present in OA joints, especially in diabetic patients (34). One potential mediator of macrophage activation is lowdensity lipoprotein (LDL) cholesterol. LDL is elevated with obesity and when oxidized stimulates the production of pro-inflammatory mediators, matrix degrading proteinases, and growth factors involved in OA pathogenesis (45). Furthermore, obesity and MetS also suppress the production of high-density lipoprotein (HDL) cholesterol, which exerts antiinflammatory effects on macrophages through down-regulation of TLR-induced proinflammatory cytokines. Mouse models of dietary and genetic-induced hypercholesterolemia increase knee OA pathology, even without increasing body weight (46-50). Moreover, statin treatment diminished OA severity in these models, supporting a direct role for cholesterol homeostasis in OA pathogenesis [reviewed in (45)]. Recent evidence also shows a role for cholesterol homeostasis in chondrocyte hypertrophy through regulation of hedgehog signaling (51), indicating multiple potential pathways linking dyslipidemia and OA pathophysiology.

\section{Infrapatellar fat pad as a local regulator of knee joint inflammation}

Abdominal adipose tissue inflammation is a central feature of dysregulated metabolism that occurs with obesity. This finding has piqued interest in the infrapatellar fat pad (IFP) as a local paracrine mediator of knee joint inflammation and OA pathogenesis. Indeed, the IFP is a source of numerous soluble factors, including cytokines (eg, IL-1, IL-4, IL-5, IL-6, IL-8, IL-13, IFN $\gamma$, TNF), chemokines (eg, CCL2), adipokines (eg, leptin, adiponectin, adipsin, resistin, and visfatin/eNAMPT), growth factors (eg, basic fibroblast growth factor and vascular endothelial growth factor), free fatty acids, and lipid derivatives (eg, arachidonic acid and prostaglandin $E_{2}$ ) [reviewed in (6)]. These factors are derived from adipocytes as well as stromal cells, including resident and infiltrating macrophages and $\mathrm{T}$ cells present within the IFP. 
The role of IFP-derived soluble factors in OA initiation and progression is unclear because the majority of studies have evaluated IFP cell populations and secreted factors in tissue harvested from joints with end-stage OA during joint replacement surgery. At this late stage of disease, the IFP contains more anti-inflammatory M2/CD206+ macrophages than proinflammatory M1/CD86+ macrophages and exerts an anti-catabolic effect on cartilage in vitro using IFP-conditioned medium (52). It is not known if these findings are unique to IFP tissue from end-stage OA joints or if these are general characteristics of IFP tissue.

Clinically, alterations in IFP magnetic resonance imaging signal intensity are significantly and positively associated with knee pain in cross-sectional and longitudinal analyses $(53,54)$. Peripatellar synovitis scores are positively associated with synovial neovascularization, hyperplasia, and villi (55), and IFP-conditioned medium stimulates the expression of proinflammatory mediators and matrix metalloproteinases in autologous fibroblast-like synoviocytes, suggesting a role for the IFP in synovial inflammation (56). Surprisingly, though, IFP size is negatively associated with knee OA prevalence and risk of progression (57). These findings imply that a larger healthy IFP protects against OA, possibly by helping to better distribute joint biomechanical stresses (57). Alternatively, IFP size could be indirectly associated with knee OA risk.

In a recent analysis of the IFP in an aging rodent model of adult-onset obesity and knee OA (58), IFP mass significantly decreased with age despite increasing total body mass. This decrease occurred independent of changes in adipocyte size, suggesting that the reduction in fat pad size with age is due to an imbalance in the rates of adipogenesis and cell death. Although the basal expression of markers for adipogenesis did not change with age, they were significantly reduced with aging following IL- $1 \beta$ stimulation, suggesting that inflammation negatively regulates IFP adipogenesis and potentially IFP size. In this model, aging increased the production of TNF and IL-13 and decreased the expression of antiinflammatory M2 macrophage markers. Thus, joint inflammation may mediate the negative association between IFP size and OA risk. Intriguingly, IL-1 $\beta$ inhibited leptin production in an age-dependent manner. This suggests that aging may protect against $\mathrm{OA}$ when joint inflammation is elevated (eg, post injury) by downregulating IFP adipogenesis and adipocyte-derived inflammatory mediators such as leptin.

Although the clinical evidence is growing that links alterations in IFP size or quality to OA risk and pain, the mechanistic understanding of these relationships is poor. Additional studies are needed at the early stages of disease to better evaluate the cause-effect relationship between IFP inflammation, size, and OA pathogenesis. Testing in multiple preclinical models of OA (eg, post-traumatic, diet-induced obesity, aging, genetic) will help to identify shared and unique mediators of IFP remodeling and inflammation by OA sub-type. Furthermore, the IFP is highly innervated with nociceptive fibers, and little is known about how changes in IFP remodeling and inflammation regulate OA pain and joint function.

\section{Energy and nutrient sensors, metabolic syndrome, and OA}

Evolutionarily conserved cellular energy and nutrient sensors, such as AMP-activated protein kinase (AMPK), sirtuins (SIRTs), and mammalian target of rapamycin (mTOR), 
determine how cells respond to excess or insufficient nutrients and changes in cellular energy balance. With the development of obesity or MetS-conditions of chronic excess nutrients-these sensors become impaired and further contribute to MetS, including abdominal adiposity, diabetes, and dyslipidemia (59-62). These changes include a decrease in AMPK and sirtuin activities and an increase in mTOR activity. Understanding how obesity and conditions that contribute to MetS also lead to aberrant AMPK, SIRT, and mTOR function provide potential clues into how metabolic derangements increase OA.

AMPK is a serine/threonine protein kinase that exists as a heterotrimeric complex consisting of a catalytic a-subunit and two regulatory $\beta$ - and $\gamma$-subunits (59). Phosphorylation of a conserved threonine residue within the activation loop of the kinase domain (Thr172) is required for the kinase activity of AMPK (59). AMPK is activated in response to decreases in cellular energy state by stimulating processes that generate ATP (e.g., fatty acid oxidation and glucose transport), and inhibiting others that consume ATP (e.g., fatty acid and protein synthesis) (59). In this manner, AMPK allows cells to adjust to changes in energy demand. Sirtuins, a conserved family composed of seven members (SIRT1-7), possess nicotinamide adenine dinucleotide $\left(\mathrm{NAD}^{+}\right)$-dependent protein deacetylase, deacylase, and ADPribosyltransferase activities (63). They guard against cellular metabolic stress by modifying the activity of metabolic enzymes and gene transcription to balance nutrient supply and demand (63). mTOR is a serine-threonine kinase that serves as a converging point for signals controlling cellular growth, energy metabolism, nutrient availability, and stress. The mTOR signaling pathway is frequently activated in various tissues during conditions of excessive nutrient intake (63). Chronic activation of mTOR signaling can lead to the development insulin resistance (63). These energy and nutrient sensors become dysfunctional when cells are exposed to obesity-associated metabolic derangements, such as high concentrations of blood glucose and fatty acids (e.g., palmitate), low-grade metabolic inflammatory mediators (e.g., TNF), and low concentrations of adiponectin $(60,64)$.

Recent studies have implicated dysfunctional AMPK, sirturin and mTOR activity in OA development and progression. Phosphorylation of AMPKa Thr172 is decreased in human knee OA chondrocytes/cartilage (65) and in mouse knee OA cartilage, compared with their respective normal counterparts (66). In addition, mouse knee cartilage exhibits an agingassociated reduction in phosphorylation of AMPKa (66). Moreover, in vitro studies demonstrate that the inflammatory cytokines IL-1 $\beta$ and TNFa, as well as biomechanical injury, can cause de-phosphorylation of AMPKa in normal articular chondrocytes. This is correlated with increased catabolic responses (e.g. increased MMP-3 and MMP-13 release). All of these effects can be inhibited by AMPK pharmacological activators $(65,66)$. Furthermore, recent in vivo studies show that activation of AMPK by berberine, a natural plant product that is known to activate AMPK, limits both surgical knee instability-induced and aging-related OA in mice (67). Collectively, sustained AMPK activity in articular chondrocytes appears to be chondroprotective.

Three members of sirtuins (SIRT1, SIRT3 and SIRT6) have been studied in articular chondrocytes. Among them, SIRT1 is best characterized so far. Similar to AMPKa phosphorylation, SIRT1 expression is decreased in both human and mouse knee OA cartilage and in aged mouse knee cartilage (68-70). Consequently, adult heterozygous Sirt1 
mice and mice with a Sirt1 point mutation lacking SIRT1 enzyme activity exhibit increased OA progression (71,72). Moreover, cartilage-specific Sirt1 knockout (KO) mice develop accelerated OA progression (70). Sustained SIRT1 expression and activity in articular chondrocytes also appears to be important for cartilage homeostasis. Indeed, SIRT1 promotes cartilage-specific gene expression (73), and activation of SIRT1 in a mouse OA model using an intra-articular injection of resveratrol significantly reduced cartilage destruction (74). Cartilage SIRT3 expression was recently shown to also decrease with age, and SIRT3 deficiency increases acetylation of the antioxidant enzyme SOD2 resulting in impaired SOD2 activity in chondrocytes (75). In addition, whole-body deletion of SIRT3 accelerates the development of knee OA (75). Expression of SIRT6 is significantly decreased in human OA chondrocytes as well (76). Depletion of SIRT6 in human chondrocytes causes increased DNA damage, telomere dysfunction, and premature senescence, which are processes implicated in cartilage degeneration in OA (77).

Activation of AMPK stimulates the expression and activity of SIRT1 in articular chondrocytes (78). Activated AMPK-SIRT1 signaling increases cellular stress resistance through downstream targets peroxisome proliferator-activated receptor $\gamma$ co-activator $1 a$ (PGC-1a, a master regulator of mitochondrial biogenesis and function) and forkhead box $\mathrm{O}$ 3a (FOXO3a, a transcription factor that regulates oxidative stress response). In this context, mitochondrial function is preserved and excessive oxidative stress and inflammationmediated matrix catabolism are inhibited $(79,80)$. Activated AMPK also protects housekeeping cellular quality control in articular chondrocytes by limiting endoplasmic reticulum (ER) stress (81) and maintains autophagy capacity (82). Activation of AMPK can promote SIRT3 expression in articular chondrocytes as well (unpublished observation). Agerelated loss of SIRT3 expression in cartilage may be a consequence of loss of AMPK activity. Loss of mitochondrial function is a hallmark of aging and age-related diseases, which is associated with reduced activity of AMPK and sirtuins $(60,63)$. Since loss of SIRT3 activity results in profound aberrations in mitochondrial function (63), AMPK-SIRT3 signaling could play an important role in maintaining normal mitochondrial function in chondrocytes.

mTOR is a potent inhibitor of autophagy, which is a cellular degradative process that maintains fundamental biological activities during cellular stresses, especially nutrient starvation (60). Activation of AMPK and SIRT1 promotes autophagy by inhibiting activity of mTOR complex (e.g. mTORC1) and enhancing the later steps in autophagosome formation through deacetylation of several autophagy-related proteins, respectively (60). Chondrocyte autophagy is reduced with a linked increase in apoptosis in human knee OA, mouse knee OA, and aged mouse knee cartilage (83). In mice, cartilage-specific genetic deletion of mTOR (84) and pharmacologic inhibition of mTOR signaling by rapamycin (85) upregulate autophagy, which reduces the severity of post-traumatic OA.

Cellular energy and nutrient sensors, in particular AMPK and sirtuins (SIRTs), are potential mediators of the systemic (plasma) and local (synovial fluid) effects of adipokines on cartilage degeneration, osteophyte formation and synovial inflammation $(86,87)$. AMPK and sirturins regulate inflammatory responses, cartilage homeostasis, and bone metabolism [reviewed in (88)]. Since dysregulation of AMPK and sirtuins are seen in experimental 
animal models of obesity and MetS, AMPK and sirtuins could be critical mediators in the cross talk between dysregulated metabolic tissues, such as adipose tissue, and joint tissues. A recent study showed significantly increased mRNA expression of inflammatory cytokines and adipokines, including TNFa, IL-6 and leptin, in the IFP of SIRT6 haploinsufficient $\left(\right.$ SIRT6 $^{+-}$) mice compared to WT mice (89). Following high-fat diet feeding, mRNA expression levels of all these cytokines were enhanced in WT and SIRT6 ${ }^{+-}$mice, with IL-6 mRNA expression further enhanced in SIRT $6^{+/-}$mice (89). Moreover, SIRT6 ${ }^{+/-}$mice exhibited accelerated cartilage degradation when fed a normal diet, and they displayed greater osteophyte formation and synovial inflammation when fed a high-fat diet (89). These results suggest that impaired SIRT6 links metabolic dysfunction with multiple aspects of OA, including cartilage degradation, synovial inflammation, and bone remodeling. Further study is warranted to investigate how energy sensors in joint tissues become dysregulated in response to abnormal systemic and/or local metabolism associated with MetS.

\section{AMPK, sirtuins and mTOR as therapeutic targets for OA}

The pathways of AMPK, sirturins and mTOR are tightly cross-linked and share many downstream targets that regulate cell processes involved in aging, including mitochondrial biogenesis, cellular metabolism, autophagy, and DNA repair (59). Increasing evidence indicates that aging, joint injury, low-grade inflammation, and possibly nutritional overload, obesity and MetS impair normal function of energy and nutrient sensors in articular cartilage. Reduced activities of AMPK and sirtuins and increased mTOR activity in articular chondrocytes trigger significant metabolic stress, manifested as mitochondrial dysfunction, oxidative stress, and inflammation. As a result, cell survival and tissue integrity and function are compromised, ultimately leading to OA development and progression (Figure 2). Interestingly, activation of AMPK and sirtuins and inhibition mTOR signaling are implicated in the beneficial effects of dietary restriction (90). In addition, some drugs already in the clinic (e.g. metformin for type 2 diabetes and methotrexate for rheumatoid arthritis), and some natural plant products used as dietary supplements (e.g. berberine, resveratrol) activate the AMPK/SIRT1 and/or AMPK/mTOR signaling pathways. As such, AMPK, sirtuins, and mTOR are potentially attractive and achievable therapeutic targets for OA. A systemic treatment (e.g. activation of AMPK) may be an effective means to combat both metabolic diseases and OA.

\section{Conclusions}

Exciting new discoveries are revealing a vast network of inter-connected pathways that regulate metabolism and inflammation. These pathways exist at the molecular level in the form of cellular energy sensors (e.g. AMPK, sirtuins, mTOR) that regulate enzyme activity, gene transcription, and proteostasis to coordinate cell survival mechanisms. They also exist at the cellular level, where changes in energy metabolism and nutrient utilization impact the activation and resolution of inflammation via effects on both immune and non-immune cells. At the organismal level, excess caloric intake, increased saturated and n-6 dietary fat, and insufficient metabolic energy expenditure can impair organ and tissue function, resulting in systems-level dysfunction (e.g. diabetes) and pathologic paracrine or endocrine proinflammatory signaling (e.g. intestinal or adipose-tissue derived inflammatory mediators). 
The increasingly recognized role of inflammation in OA, together with the high comorbidity of obesity and OA, set an exciting new path for trying to understand how disrupted metabolic signaling in distant organs or in local articular tissues contribute to an increase in OA risk.

Current prospective epidemiological studies show clear associations between OA, the MetS, and its components, even when controlling for obesity in some studies. Animal models that recapitulate some aspects of the MetS also support a role for disrupted metabolic and inflammatory signaling in OA risk independent of obesity itself. Many questions remain, however, about the nature of these interactions. Despite a growing body of clinical evidence on sex-specific associations between components of the MetS and OA, few animal studies have tested sex-dependent outcomes in obese OA models. Additional questions remain about the relative role of systemic versus local factors in regulating articular joint tissue inflammation and metabolism. Therefore, we propose the following research agenda to address these questions and additional unmet needs to better understand how metabolic dysfunction mediates joint inflammation and the pathophysiology of OA.

\section{Acknowledgments}

This work has been supported by grants from the ROAD-Foundation Arthritis Network and the French Society of Rheumatology (FB), the NIH (National Institute of Arthritis and Musculoskeletal and Skin Diseases grant R03AR066828 and National Institute on Aging grant R01AG049058 to TMG), and the Department Veterans Affairs grant 1I01BX002234 (RLB). The content is solely the responsibility of the authors and does not necessarily represent the official views of the funding agencies

\section{References}

1. Felson DT. Osteoarthritis as a disease of mechanics. Osteoarthritis Cartilage. 2013; 21:10-15. [PubMed: 23041436]

2. Berenbaum F. Osteoarthritis as an inflammatory disease (osteoarthritis is not osteoarthrosis!). Osteoarthritis Cartilage. 2013; 21:16-21. [PubMed: 23194896]

3. Ayral X, Pickering EH, Woodworth TG, Mackillop N, Dougados M. Synovitis: a potential predictive factor of structural progression of medial tibiofemoral knee osteoarthritis - results of a 1 year longitudinal arthroscopic study in 422 patients. Osteoarthritis Cartilage. 2005; 13:361-367. [PubMed: 15882559]

4. Sellam J, Berenbaum F. The role of synovitis in pathophysiology and clinical symptoms of osteoarthritis. Nat Rev Rheumatol. 2010; 6:625-635. [PubMed: 20924410]

5. Yusuf E, Nelissen RG, Ioan-Facsinay A, Stojanovic-Susulic V, DeGroot J, van Osch G, et al. Association between weight or body mass index and hand osteoarthritis: a systematic review. Annals of the Rheumatic Diseases. 2010; 69:761-765. [PubMed: 19487215]

6. Ioan-Facsinay A, Kloppenburg M. An emerging player in knee osteoarthritis: the infrapatellar fat pad. Arthritis Res Ther. 2013; 15:225. [PubMed: 24367915]

7. Puenpatom RA, Victor TW. Increased prevalence of metabolic syndrome in individuals with osteoarthritis: an analysis of NHANES III data. Postgrad Med. 2009; 121:9-20. [PubMed: 19940413]

8. Yoshimura N, Muraki S, Oka H, Kawaguchi H, Nakamura K, Akune T. Association of Knee Osteoarthritis with the Accumulation of Metabolic Risk Factors Such as Overweight, Hypertension, Dyslipidemia, and Impaired Glucose Tolerance in Japanese Men and Women: The ROAD Study. J Rheumatol. 2011; 38:921-930. [PubMed: 21324967]

9. Shin D. Association between metabolic syndrome, radiographic knee osteoarthritis, and intensity of knee pain: results of a national survey. J Clin Endocrinol Metab. 2014; 99:3177-3183. [PubMed: 24780047] 
10. Michishita R, Shono N, Kasahara T, Katoku M, Tsuruta T. The possible influence of osteoarthritis of the knee on the accumulation of coronary risk factors in postmenopausal obese women. Obes Res Clin Pract. 2008; 2:I-II.

11. Lee S, Kim T-N, Kim S-H, Kim Y-G, Lee C-K, Moon H-B, et al. Obesity, metabolic abnormality, and knee osteoarthritis: a cross-sectional study in Korean women. Mod Rheumatol. 2015; 25:292297. [PubMed: 25065916]

12. Calvet J, Orellana C, Larrosa M, Navarro N, Chillarón JJ, Pedro-Botet J, et al. High prevalence of cardiovascular co-morbidities in patients with symptomatic knee or hand osteoarthritis. Scand J Rheumatol. 2015; 45:1-4.

13. Engström G, Gerhardsson de Verdier M, Rollof J, Nilsson PM, Lohmander LS. C-reactive protein, metabolic syndrome and incidence of severe hip and knee osteoarthritis. A population-based cohort study Osteoarthritis Cartilage. 2009; 17:168-173. [PubMed: 18760940]

14. Tomi A-L, Sellam J, Lacombe K, Fellahi S, Sebire M, Rey-Jouvin C, et al. Increased prevalence and severity of radiographic hand osteoarthritis in patients with HIV-1 infection associated with metabolic syndrome: data from the cross-sectional METAFIB-OA study. Ann Rheum Dis. 2016 Online First-published on March 31-2016 as 10.1136-annrheumdis-2016-209262.

15. Visser AW, de Mutsert R, le Cessie S, Heijer den M, Rosendaal FR, Kloppenburg M, et al. The relative contribution of mechanical stress and systemic processes in different types of osteoarthritis: the NEO study. Ann Rheum Dis. 2015; 74:1842-1847. [PubMed: 24845389]

16. Sowers M, Karvonen-Gutierrez CA, Palmieri-Smith R, Jacobson JA, Jiang Y, Ashton-Miller JA. Knee osteoarthritis in obese women with cardiometabolic clustering. Arthritis Rheum. 2009; 61:1328-1336. [PubMed: 19790111]

17. Yoshimura N, Muraki S, Oka H, Tanaka S, Kawaguchi H, Nakamura K, et al. Accumulation of metabolic risk factors such as overweight, hypertension, dyslipidaemia, and impaired glucose tolerance raises the risk of occurrence and progression of knee osteoarthritis: a 3-year follow-up of the ROAD study. Osteoarthritis Cartilage. 2012; 20:1217-1226. [PubMed: 22796312]

18. Monira Hussain S, Wang Y, Cicuttini FM, Simpson JA, Giles GG, Graves S, et al. Incidence of total knee and hip replacement for osteoarthritis in relation to the metabolic syndrome and its components: A prospective cohort study. Seminars in arthritis and rheumatism. 2014; 43:429-436. [PubMed: 24012045]

19. Schett G, Kleyer A, Perricone C, Sahinbegovic E, Iagnocco A, Zwerina J, et al. Diabetes is an independent predictor for severe osteoarthritis: results from a longitudinal cohort study. Diabetes Care. 2013; 36:403-409. [PubMed: 23002084]

20. Davies-Tuck ML, Hanna F, Davis SR, Bell RJ, Davison SL, Wluka AE, et al. Total cholesterol and triglycerides are associated with the development of new bone marrow lesions in asymptomatic middle-aged women - a prospective cohort study. Arthritis Res Ther. 2009; 11:R181. [PubMed: 19961577]

21. Hoeven TA, Kavousi M, Clockaerts S, Kerkhof HJM, van Meurs JB, Franco O, et al. Association of atherosclerosis with presence and progression of osteoarthritis: the Rotterdam Study. Ann Rheum Dis. 2013; 72:646-651. [PubMed: 22563029]

22. King KB, Rosenthal AK. The adverse effects of diabetes on osteoarthritis: update on clinical evidence and molecular mechanisms. Osteoarthritis Cartilage. 2015; 23:841-850. [PubMed: 25837996]

23. Conaghan PG, Vanharanta H, Dieppe PA. Is progressive osteoarthritis an atheromatous vascular disease? Ann Rheum Dis. 2005; 64:1539-1541. [PubMed: 16107512]

24. Stürmer T, Sun Y, Sauerland S, Zeissig I, Gunther KP, Puhl W, et al. Serum cholesterol and osteoarthritis. The baseline examination of the Ulm Osteoarthritis Study. J Rheumatol. 1998; 25:1827-1832. [PubMed: 9733467]

25. Addimanda O, Mancarella L, Dolzani P, Ramonda R, Fioravanti A, Brusi V, et al. Clinical associations in patients with hand osteoarthritis. Scand J Rheumatol. 2012; 41:310-313. [PubMed: 22455607]

26. Berry PA, Jones SW, Cicuttini FM, Wluka AE, Maciewicz RA. Temporal relationship between serum adipokines, biomarkers of bone and cartilage turnover, and cartilage volume loss in a 
population with clinical knee osteoarthritis. Arthritis Rheum. 2011; 63:700-707. [PubMed: 21305502]

27. Van Spil WE, Welsing PMJ, Kloppenburg M, Bierma-Zeinstra SM, Bijlsma JWJ, Mastbergen SC, et al. Cross-sectional and predictive associations between plasma adipokines and radiographic signs of early-stage knee osteoarthritis: data from CHECK. Osteoarthritis Cartilage. 2012; 20:1278-1285. [PubMed: 22890184]

28. Yusuf E, Ioan-Facsinay A, Bijsterbosch J, Klein-Wieringa I, Kwekkeboom J, Slagboom PE, et al. Association between leptin, adiponectin and resistin and long-term progression of hand osteoarthritis. Ann Rheum Dis. 2011; 70:1282-1284. [PubMed: 21470970]

29. Silberberg M, Silberberg R. Effects of a high fat diet on the joints of aging mice. AMA Arch Pathol. 1950; 50:828-846. [PubMed: 14789326]

30. Griffin TM, Fermor B, Huebner JL, Kraus VB, Rodriguiz RM, Wetsel WC, et al. Diet-induced obesity differentially regulates behavioral, biomechanical, and molecular risk factors for osteoarthritis in mice. Arthritis Res Ther. 2010; 12:R130. [PubMed: 20604941]

31. Griffin TM, Huebner JL, Kraus VB, Yan Z, Guilak F. Induction of osteoarthritis and metabolic inflammation by a very high-fat diet in mice: Effects of short-term exercise. Arthritis Rheum. 2012; 64:443-453. [PubMed: 21953366]

32. Collins KH, Paul HA, Reimer RA, Seerattan RA, Hart DA, Herzog W. Relationship between inflammation, the gut microbiota, and metabolic osteoarthritis development: studies in a rat model. Osteoarthritis Cartilage. 2015; 23:1989-1998. [PubMed: 26521745]

33. Louer CR, Furman BD, Huebner JL, Kraus VB, Olson SA, Guilak F. Diet-induced obesity significantly increases the severity of posttraumatic arthritis in mice. Arthritis Rheum. 2012; 64:3220-3230. [PubMed: 22576842]

34. Hamada D, Maynard R, Schott E, Drinkwater CJ, Ketz JP, Kates SL, et al. Insulin suppresses TNFdependent early osteoarthritic changes associated with obesity and type 2 diabetes. Arthritis Rheum. 2015

35. Griffin TM, Huebner JL, Kraus VB, Guilak F. Extreme obesity due to impaired leptin signaling in mice does not cause knee osteoarthritis. Arthritis Rheum. 2009; 60:2935-2944. [PubMed: 19790050]

36. Griffin TM, Guilak F. Why is obesity associated with osteoarthritis? Insights from mouse models of obesity. Biorheology. 2008; 45:387-398. [PubMed: 18836239]

37. Huang M-J, Wang L, Jin D-D, Zhang Z-M, Chen T-Y, Jia C-H, et al. Enhancement of the synthesis of n-3 PUFAs in fat-1 transgenic mice inhibits mTORC1 signalling and delays surgically induced osteoarthritis in comparison with wild-type mice. Ann Rheum Dis. 2014; 73:1719-1727. [PubMed: 23852692]

38. Wu C-L, Jain D, McNeill JN, Little D, Anderson JA, Huebner JL, et al. Dietary fatty acid content regulates wound repair and the pathogenesis of osteoarthritis following joint injury. Ann Rheum Dis. 2015; 74:2076-2083. [PubMed: 25015373]

39. Cai A, Hutchison E, Hudson J, Kawashima Y, Komori N, Singh A, et al. Metabolic enrichment of omega-3 polyunsaturated fatty acids does not reduce the onset of idiopathic knee osteoarthritis in mice. Osteoarthritis Cartilage. 2014; 22:1301-1309. [PubMed: 25008209]

40. Zainal Z, Longman AJ, Hurst S, Duggan K, Caterson B, Hughes CE, et al. Relative efficacies of omega-3 polyunsaturated fatty acids in reducing expression of key proteins in a model system for studying osteoarthritis. Osteoarthritis Cartilage. 2009; 17:896-905. [PubMed: 19217322]

41. Hill CL, March LM, Aitken D, Lester SE, Battersby R, Hynes K, et al. Fish oil in knee osteoarthritis: a randomised clinical trial of low dose versus high dose. Ann Rheum Dis. 2016; 75:23-29. [PubMed: 26353789]

42. Collins KH, Paul HA, Reimer RA, Seerattan RA, Hart DA, Herzog W. Relationship between inflammation, the gut microbiota, and metabolic osteoarthritis development: studies in a rat model. Osteoarthritis Cartilage. 2015; 23:1989-1998. [PubMed: 26521745]

43. Kc R, Voigt R, Li X, Forsyth CB, Ellman MB, Summa KC, et al. Induction of Osteoarthritis-like Pathologic Changes by Chronic Alcohol Consumption in an Experimental Mouse Model. Arthritis Rheumatol. 2015; 67:1678-1680. [PubMed: 25708245] 
44. Huang Z, Kraus VB. Does lipopolysaccharide-mediated inflammation have a role in OA? Nat Rev Rheumatol. 2016; 12:123-129. [PubMed: 26656661]

45. de Munter W, van der Kraan PM, van den Berg WB, van Lent PLEM. High systemic levels of lowdensity lipoprotein cholesterol: fuel to the flames in inflammatory osteoarthritis? Rheumatology (Oxford). 2016; 55:16-24. [PubMed: 26231344]

46. Gierman LM, van der Ham F, Koudijs A, Wielinga PY, Kleemann R, Kooistra T, et al. Metabolic stress-induced inflammation plays a major role in the development of osteoarthritis in mice. Arthritis Rheum. 2012; 64:1172-1181. [PubMed: 22034049]

47. Triantaphyllidou I-E, Kalyvioti E, Karavia E, Lilis I, Kypreos KE, Papachristou DJ. Perturbations in the HDL metabolic pathway predispose to the development of osteoarthritis in mice following long-term exposure to western-type diet. Osteoarthritis Cartilage. 2013; 21:322-330. [PubMed: 23151457]

48. de Munter W, Blom AB, Helsen MM, Walgreen B, van der Kraan PM, Joosten LAB, et al. Cholesterol accumulation caused by low density lipoprotein receptor deficiency or a cholesterolrich diet results in ectopic bone formation during experimental osteoarthritis. Arthritis Res Ther. 2013; 15:R178. [PubMed: 24286458]

49. Gierman LM, Kühnast S, Koudijs A, Pieterman EJ, Kloppenburg M, van Osch GJVM, et al. Osteoarthritis development is induced by increased dietary cholesterol and can be inhibited by atorvastatin in APOE*3Leiden. CETP mice-a translational model for atherosclerosis. Ann Rheum Dis. 2014; 73:921-927. [PubMed: 23625977]

50. de Munter W, van den Bosch MH, Slöetjes AW, Croce KJ, Vogl T, Roth J. High LDL levels lead to increased synovial inflammation and accelerated ectopic bone formation during experimental osteoarthritis. Osteoarthritis Cartilage. 2015

51. Ali SA, Al-Jazrawe M, Ma H, Whetstone H, Poon R, Farr S, et al. Regulation of Cholesterol Homeostasis by Hedgehog Signaling in Osteoarthritic Cartilage. Arthritis Rheumatol. 2016; 68:127-137. [PubMed: 26315393]

52. Bastiaansen-Jenniskens YM, Clockaerts S, Feijt C, Zuurmond A-M, Stojanovic-Susulic V, Bridts $\mathrm{C}$, et al. Infrapatellar fat pad of patients with end-stage osteoarthritis inhibits catabolic mediators in cartilage. Ann Rheum Dis. 2012; 71:288-294. [PubMed: 21998115]

53. Hill CL, Hunter DJ, Niu J, Clancy M, Guermazi A, Genant H, et al. Synovitis detected on magnetic resonance imaging and its relation to pain and cartilage loss in knee osteoarthritis. Ann Rheum Dis. 2007; 66:1599-1603. [PubMed: 17491096]

54. Han W, Aitken D, Zhu Z, Halliday A, Wang X, Antony B, et al. Signal intensity alteration in the infrapatellar fat pad at baseline for the prediction of knee symptoms and structure in older adults: a cohort study. Ann Rheum Dis. 2015 published online first on November 26-2015 as 10.1136annrheumdis-2015-208360.

55. de Lange-Brokaar BJE, Ioan-Facsinay A, Yusuf E, Visser AW, Kroon HM, Andersen SN, et al. Degree of synovitis on MRI by comprehensive whole knee semi-quantitative scoring method correlates with histologic and macroscopic features of synovial tissue inflammation in knee osteoarthritis. Osteoarthritis Cartilage. 2014; 22:1606-1613. [PubMed: 24365722]

56. Eymard F, Pigenet A, Citadelle D, Flouzat-Lachaniette C-H, Poignard A, Benelli C, et al. Induction of an inflammatory and prodegradative phenotype in autologous fibroblast-like synoviocytes by the infrapatellar fat pad from patients with knee osteoarthritis. Arthritis Rheumatol. 2014; 66:2165-2174. [PubMed: 24719336]

57. Pan F, Han W, Wang X, Liu Z, Jin X, Antony B, et al. A longitudinal study of the association between infrapatellar fat pad maximal area and changes in knee symptoms and structure in older adults. Ann Rheum Dis. 2015; 74:1818-1824. [PubMed: 24833783]

58. Fu Y, Huebner JL, Kraus VB, Griffin TM. Effect of Aging on Adipose Tissue Inflammation in the Knee Joints of F344BN Rats. The Journals of Gerontology Series A: Biological Sciences and Medical Sciences. 2015:glv151.

59. Steinberg GR, Kemp BE. AMPK in Health and Disease. Physiological Reviews. 2009; 89:10251078. [PubMed: 19584320] 
60. Salminen A, Kaarniranta K. AMP-activated protein kinase (AMPK) controls the aging process via an integrated signaling network. Ageing Research Reviews. 2012; 11:230-241. [PubMed: 22186033]

61. Chalkiadaki A, Guarente L. Sirtuins mediate mammalian metabolic responses to nutrient availability. Nat Rev Endocrinol. 2012; 8:287-296. [PubMed: 22249520]

62. Jia G, Aroor AR, Martinez-Lemus LA, Sowers JR. Overnutrition, mTOR signaling, and cardiovascular diseases. AJP: Regulatory, Integrative and Comparative Physiology. 2014; 307:R1198-206.

63. Giblin W, Skinner ME, Lombard DB. Sirtuins: guardians of mammalian healthspan. Trends Genet. 2014; 30:271-286. [PubMed: 24877878]

64. Weikel KA, Ruderman NB, Cacicedo JM. Unraveling the actions of AMP-activated protein kinase in metabolic diseases: Systemic to molecular insights. Metab Clin Exp. 2016; 65:634-645. [PubMed: 27085772]

65. Terkeltaub R, Yang B, Lotz M, Liu-Bryan R. Chondrocyte AMP-activated protein kinase activity suppresses matrix degradation responses to proinflammatory cytokines interleukin- $1 \beta$ and tumor necrosis factor a. Arthritis Rheum. 2011; 63:1928-1937. [PubMed: 21400477]

66. Petursson F, Husa M, June R, Lotz M, Terkeltaub R, Liu-Bryan R. Linked decreases in liver kinase $\mathrm{B} 1$ and AMP-activated protein kinase activity modulate matrix catabolic responses to biomechanical injury in chondrocytes. Arthritis Res Ther. 2013; 15:R77. [PubMed: 23883619]

67. Bryan R, Zhao X, Wang Y, Lee HS, Kim H, Akasdi A, et al. Activation of AMP-Activated Protein Kinase (AMPK) By Berberine Limits Both Surgical Knee Instability-Induced and Aging-Related Osteoarthritis in Mice. Arthritis \& Rheumatology. 2014; 66:S1288-S1289.

68. Dvir-Ginzberg M, Steinmeyer J. Towards elucidating the role of SirT1 in osteoarthritis. Front Biosci. 2013; 18:343-355.

69. Fujita N, Matsushita T, Ishida K, Kubo S, Matsumoto T, Takayama K, et al. Potential involvement of SIRT1 in the pathogenesis of osteoarthritis through the modulation of chondrocyte gene expressions. J Orthop Res. 2011; 29:511-515. [PubMed: 21337390]

70. Matsuzaki T, Matsushita T, Takayama K, Matsumoto T, Nishida K, Kuroda R, et al. Disruption of Sirt1 in chondrocytes causes accelerated progression of osteoarthritis under mechanical stress and during ageing in mice. Ann Rheum Dis. 2014; 73:1397-1404. [PubMed: 23723318]

71. Gabay O, Oppenhiemer H, Meir H, Zaal K, Sanchez C, Dvir-Ginzberg M. Increased apoptotic chondrocytes in articular cartilage from adult heterozygous SirT1 mice. Ann Rheum Dis. 2012; 71:613-616. [PubMed: 22258484]

72. Gabay O, Sanchez C, Dvir-Ginzberg M, Gagarina V, Zaal KJ, Song Y, et al. Sirtuin 1 enzymatic activity is required for cartilage homeostasis in vivo in a mouse model. Arthritis Rheum. 2012; 65:159-166.

73. Dvir-Ginzberg M, Gagarina V, Lee EJ, Hall DJ. Regulation of cartilage-specific gene expression in human chondrocytes by SirT1 and nicotinamide phosphoribosyltransferase. J Biol Chem. 2008; 283:36300-36310. [PubMed: 18957417]

74. Li W, Cai L, Zhang Y, Cui L, Shen G. Intra-articular resveratrol injection prevents osteoarthritis progression in a mouse model by activating SIRT1 and thereby silencing HIF-2a. J Orthop Res. 2015; 33:1061-1070. [PubMed: 25737402]

75. Fu Y, Kinter M, Hudson J, Humphries KM, Lane RS, White JR, et al. Aging Promotes SIRT3dependent Cartilage SOD2 Acetylation and Osteoarthritis. Arthritis Rheumatol. 2016 "Accepted Article"-doi: 10.1002-art.39618.

76. Wu Y, Chen L, Wang Y, Li W, Lin Y, Yu D, et al. Overexpression of Sirtuin 6 suppresses cellular senescence and NF- $\mathrm{kB}$ mediated inflammatory responses in osteoarthritis development. Sci Rep. 2015; 5:17602. [PubMed: 26639398]

77. Nagai K, Matsushita T, Matsuzaki T, Takayama K, Matsumoto T, Kuroda R, et al. Depletion of SIRT6 causes cellular senescence, DNA damage, and telomere dysfunction in human chondrocytes. Osteoarthritis Cartilage. 2015; 23:1412-1420. [PubMed: 25819580]

78. Ruderman NB, Julia Xu X, Nelson L, Cacicedo JM, Saha AK, Lan F, et al. AMPK and SIRT1: a long-standing partnership? AJP: Endocrinology and Metabolism. 2010; 298:E751-E760. 
79. Wang Y, Zhao X, Lotz M, Terkeltaub R, Liu-Bryan R. Mitochondrial biogenesis is impaired in osteoarthritic chondrocytes but reversible via peroxisome proliferator-activated receptor- $\gamma$ coactivator 1a. Arthritis Rheumatol. 2015

80. Zhao X, Petursson F, Viollet B, Lotz M, Terkeltaub R, Liu-Bryan R. Peroxisome ProliferatorActivated Receptor $\gamma$ Coactivator $1 a$ and FoxO3A Mediate Chondroprotection by AMP-Activated Protein Kinase. Arthritis Rheumatol. 2014; 66:3073-3082. [PubMed: 25047750]

81. Husa M, Petursson F, Lotz M, Terkeltaub R, Liu-Bryan R. C/EBP homologous protein drives procatabolic responses in chondrocytes. Arthritis Res Ther. 2013; 15:R218. [PubMed: 24351550]

82. Bohensky J, Leshinsky S, Srinivas V, Shapiro IM. Chondrocyte autophagy is stimulated by HIF-1 dependent AMPK activation and mTOR suppression. Pediatr Nephrol. 2010; 25:633-642. [PubMed: 19830459]

83. Caramés B, Taniguchi N, Otsuki S, Blanco FJ, Lotz M. Autophagy is a protective mechanism in normal cartilage, and its aging-related loss is linked with cell death and osteoarthritis. Arthritis Rheum. 2010; 62:791-801. [PubMed: 20187128]

84. Zhang Y, Vasheghani F, Li Y-H, Blati M, Simeone K, Fahmi H, et al. Cartilage-specific deletion of mTOR upregulates autophagy and protects mice from osteoarthritis. Ann Rheum Dis. 2014

85. Caramés B, Hasegawa A, Taniguchi N, Miyaki S, Blanco FJ, Lotz M. Autophagy activation by rapamycin reduces severity of experimental osteoarthritis. Ann Rheum Dis. 2012; 71:575-581. [PubMed: 22084394]

86. Poonpet T, Honsawek S. Adipokines: Biomarkers for osteoarthritis? World J Orthop. 2014; 5:319_ 327. [PubMed: 25035835]

87. Neumann E, Junker S, Schett G, Frommer K, Müller-Ladner U. Adipokines in bone disease. Nat Rev Rheumatol. 2016; 12:296-302. [PubMed: 27080691]

88. Liu-Bryan R. Inflammation and intracellular metabolism: new targets in OA. Osteoarthritis Cartilage. 2015; 23:1835-1842. [PubMed: 26521729]

89. Ailixiding M, Aibibula Z, Iwata M, Piao J, Hara Y, Koga D, et al. Pivotal role of Sirt6 in the crosstalk among ageing, metabolic syndrome and osteoarthritis. Biochemical and Biophysical Research Communications. 2015; 466:319-326. [PubMed: 26362183]

90. Solon-Biet SM, Mitchell SJ, de Cabo R, Raubenheimer D, Le Couteur DG, Simpson SJ. Macronutrients and caloric intake in health and longevity. The Journal of endocrinology. 2015; 226:R17-28. [PubMed: 26021555]

91. Aibibula Z, Ailixiding M, Iwata M, Piao J, Hara Y, Okawa A, et al. Xanthine oxidoreductase activation is implicated in the onset of metabolic arthritis. Biochemical and Biophysical Research Communications. 2016; 472:26-32. [PubMed: 26903297]

92. Mooney RA, Sampson ER, Lerea J, Rosier RN, Zuscik MJ. High-fat diet accelerates progression of osteoarthritis after meniscal/ligamentous injury. Arthritis Res Ther. 2011; 13:R198. [PubMed: 22152451] 


\section{Research Agenda}

- To design an epidemiological prospective study looking at the risk of hand $\mathrm{OA}$ in presence of MetS

- To design an epidemiological prospective study looking at the risk of knee/hip/hand OA in presence of hypertension

- $\quad$ To design studies and develop model systems evaluating sex-dependent differences in $\mathrm{OA}$ risk in the presence of MetS and its underlying components

- To design studies and develop model systems that isolate the effects of body weight, MetS components, and aging on tissue-specific cellular and molecular mediators of articular joint inflammation and metabolism

- To develop methods and model systems to evaluate in vivo cellular energy metabolism and metabolic signaling networks within and between articular joint tissues under physiologic and pathophysiologic conditions

- To design clinical and preclinical studies that test the efficacy of metabolicbased therapies (e.g., dietary, natural products, pharmaceutical) on OA risk in the presence of obesity and MetS 


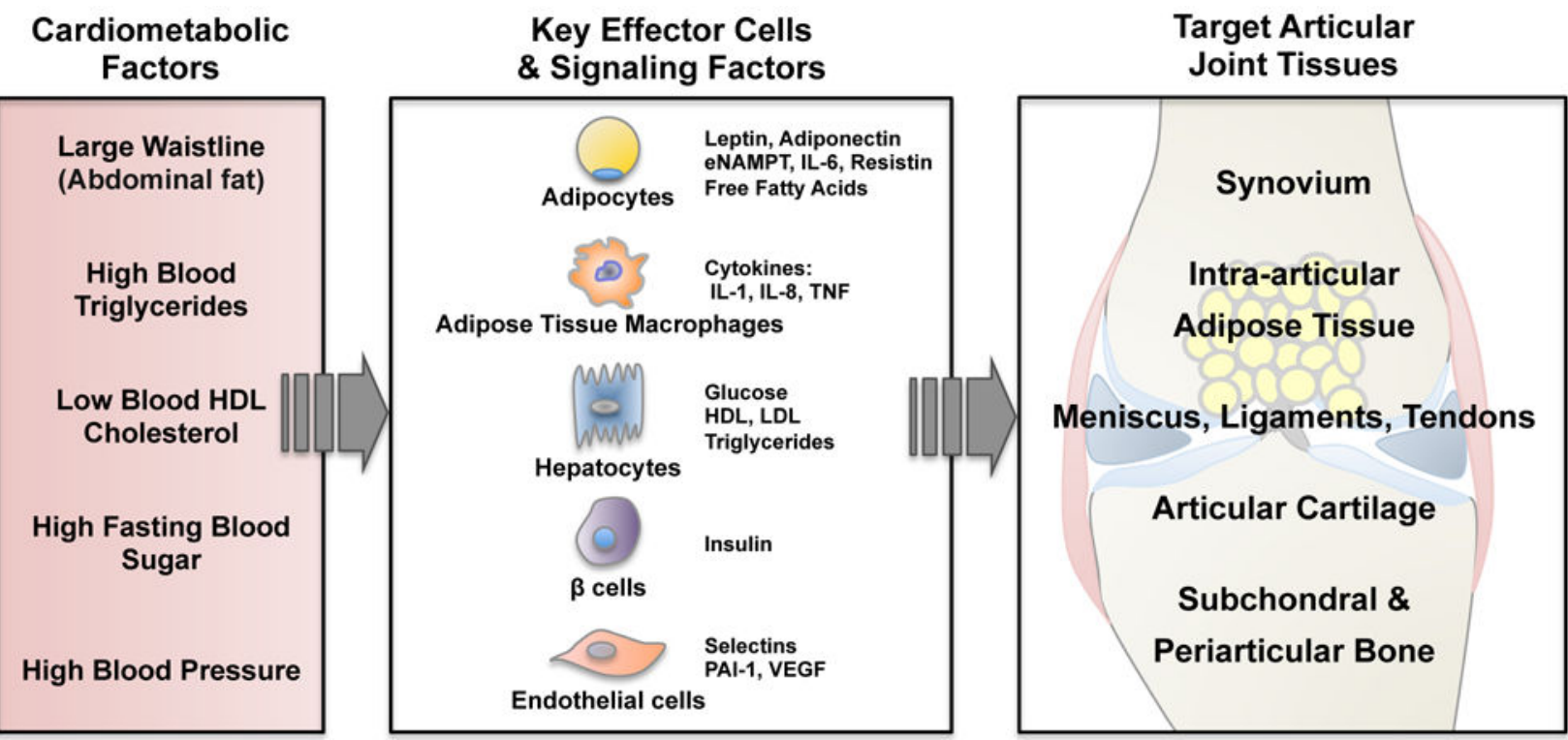

Figure 1. Cardiometabolic factors and associated mediators of increased OA pathophysiology The clustering of cardiometabolic conditions that collectively increase the risk of heart disease, diabetes, and stroke are referred to as the Metabolic Syndrome (MetS). Emerging data indicate that the MetS also increases OA risk by impairing the regulation of numerous metabolic and inflammatory pathways, including adipose tissue inflammation, blood glucose and lipid homeostasis, and vascular inflammation. Dysregulation of these signaling pathways impact multiple articular joint tissues either directly or indirectly through disrupted tissue paracrine signaling and/or biomechanical function. The net result is an increase in synovial and intra-articular fat inflammation, impaired bone remodeling, and the suppression of cartilage anabolic activity in favor of catabolism. 
Aging

$>$ Joint injury

> Inflammation

> Nutritional overload*

$>$ Obesity ${ }^{\star}$, MetS$^{*}$

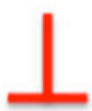

> Dietary restriction*

- Natural plant products (e.g. berberine, resveratrol)

$>$ Drugs (e.g. metformin*, methotrexate*)

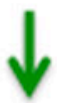

\section{Activities of energy sensors (AMPK, sirtuins) in articular chondrocytes}

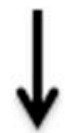

Maintaining normal mitochondrial function
Preserving cellular quality control systems

Limiting excessive oxidative stress

Inhibiting excessive cartilage catabolism

$\sqrt{6}$

Articular cartilage homeostasis

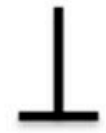

\section{OA development and progression}

Figure 2. AMPK and sirtuins as potential therapeutic targets for $\mathrm{OA}$

Aging, joint injury, low-grade inflammation, and possibly altered metabolism resulted from nutritional overload, obesity or MetS impair activities energy sensors AMPK and sirtuins in articular cartilage. In turn, the dysregulated signaling of AMPK and/or sirtuins triggers significant chondrocyte stress by inducing mitochondrial dysfunction, oxidative stress, and inflammation and weakening cellular quality control that compromise cell survival and cartilage tissue integrity, ultimately leading to OA development and progression. However, targeted activation of AMPK and sirtuins potentially by dietary restriction, natural plant products used as dietary supplements (e.g. berberine, resveratrol), and drugs already in the clinic (e.g. metformin for type 2 diabetes, methotrexate for rheumatoid arthritis) could be an attractive therapeutic strategy for OA, particularly for those OA patients who also have MetS. Note: *predicted pathways. 


\begin{tabular}{|c|c|c|c|c|}
\hline & 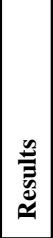 & 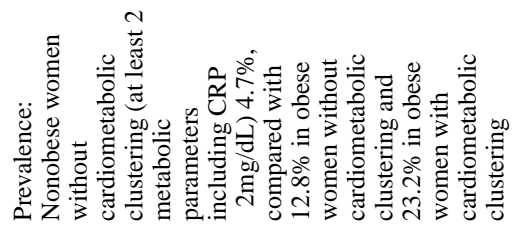 & 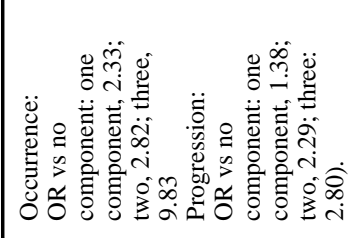 & 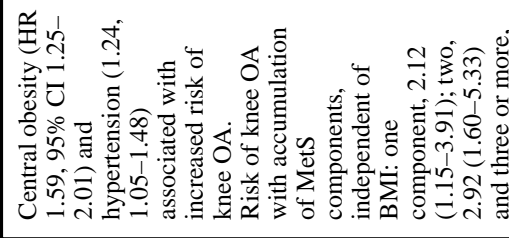 \\
\hline & 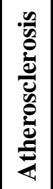 & 之 & 令 & 令 \\
\hline & 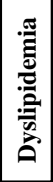 & 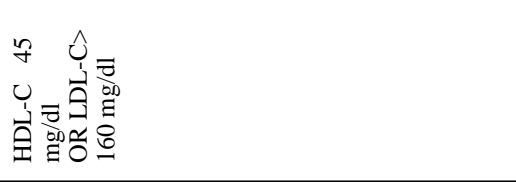 & 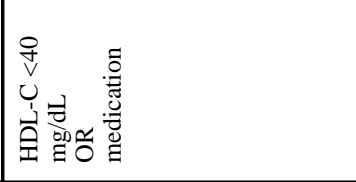 & 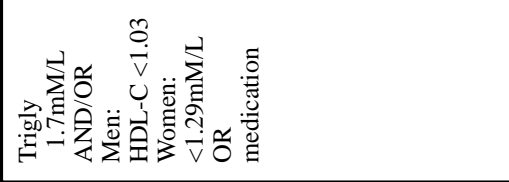 \\
\hline$\stackrel{\mathscr{\Xi}}{\Xi}$ & 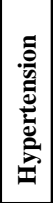 & 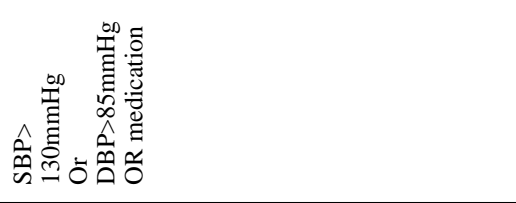 & 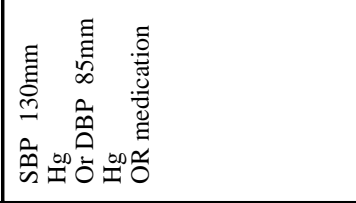 & 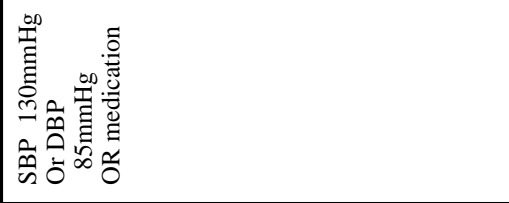 \\
\hline 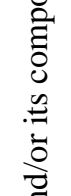 & 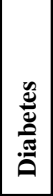 & 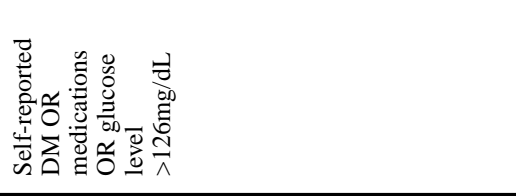 & 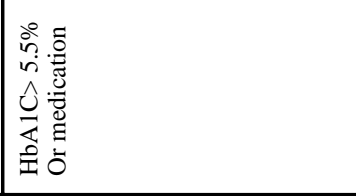 & 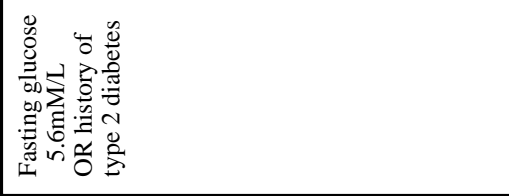 \\
\hline 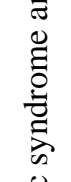 & 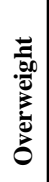 & 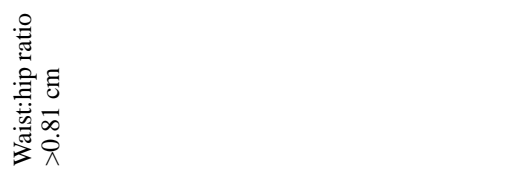 & $\mid \begin{array}{l}n \\
\hat{i} \\
\hat{\sum} \\
\sum_{m} \underline{z}\end{array}$ & 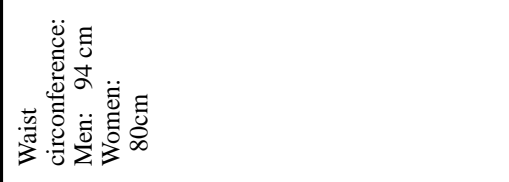 \\
\hline 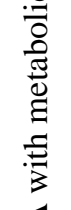 & 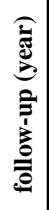 & 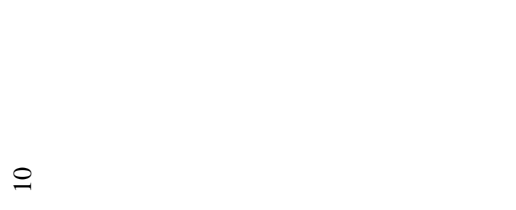 & $m$ & $\mid \begin{aligned} & n \\
\infty & \pi \\
0 & \pi\end{aligned}$ \\
\hline$\overbrace{4}^{0}$ & $\overleftarrow{0}$ & $\forall$ & 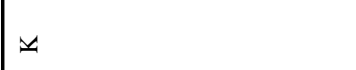 & $\forall x$ \\
\hline 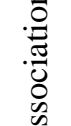 & $\sum$ & $\begin{array}{l}\mathscr{O} \\
\stackrel{\alpha}{O}\end{array}$ & 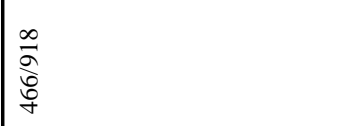 & 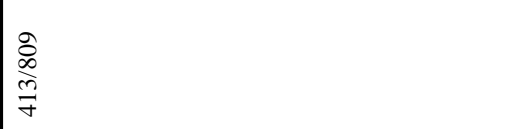 \\
\hline 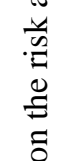 & 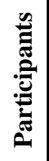 & $\underset{\mathscr{\alpha}}{\stackrel{\widetilde{\alpha}}{2}}$ & $\mid \begin{array}{l}+ \\
\stackrel{\infty}{2}\end{array}$ & ปี \\
\hline 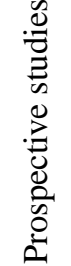 & & 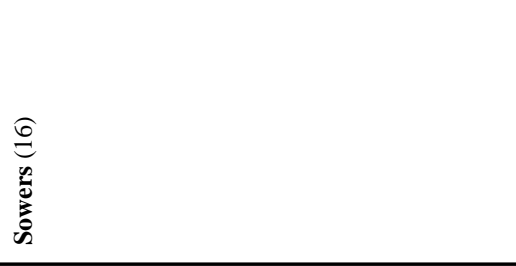 & 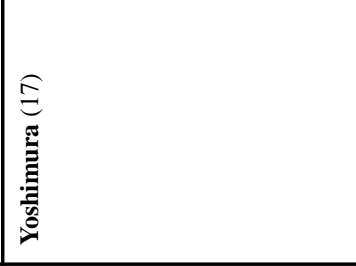 & 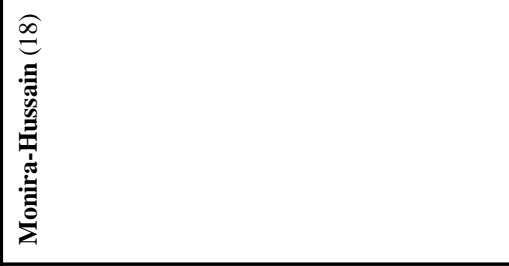 \\
\hline
\end{tabular}




\begin{tabular}{|c|c|c|c|c|c|}
\hline & 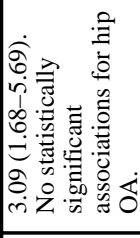 & 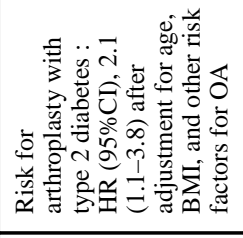 & 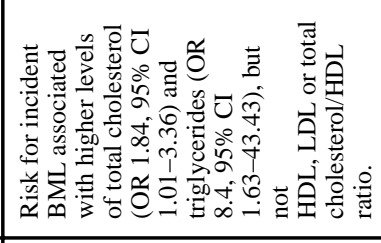 & 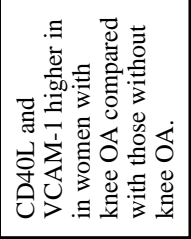 & 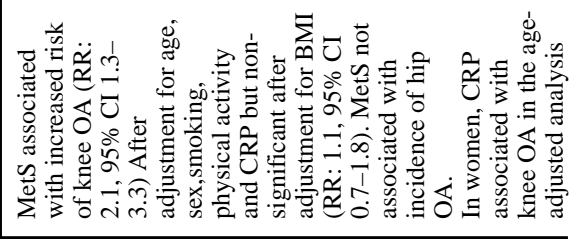 \\
\hline 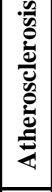 & & z & 童 & 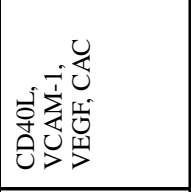 & 立 \\
\hline 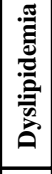 & & 立 & z & ह & 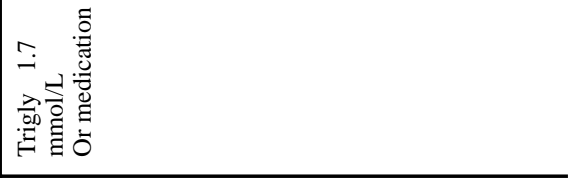 \\
\hline 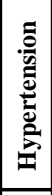 & & $\hat{z}$ & 立 & 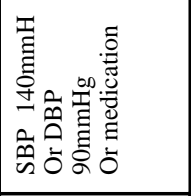 & 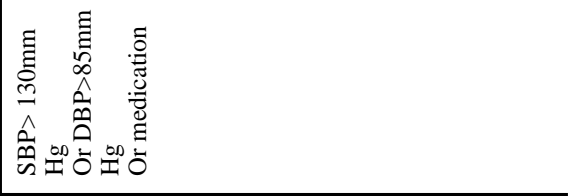 \\
\hline 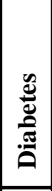 & & 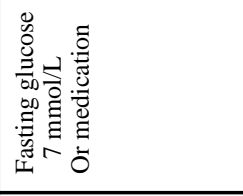 & 立 & $\hat{z}$ & 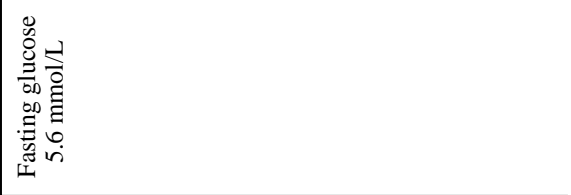 \\
\hline 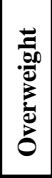 & & 之 & 立 & $\hat{z}$ & 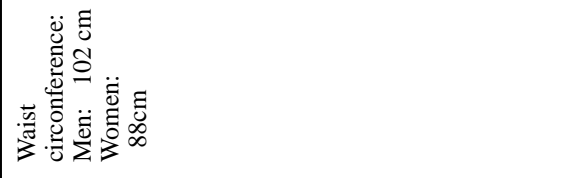 \\
\hline 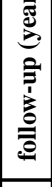 & & 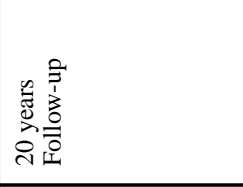 & 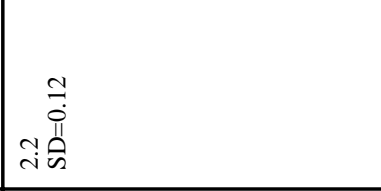 & 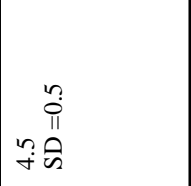 & $\stackrel{ \pm}{ \pm}$ \\
\hline$\overleftarrow{0}$ & & $\because I$ & $\because$ & $\longleftarrow$ & $\forall I$ \\
\hline$\frac{5}{2}$ & & $\frac{\substack{y \\
\bar{y}}}{\bar{y}}$ & †̊ & 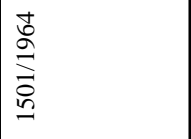 & 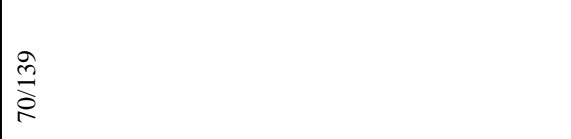 \\
\hline 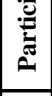 & & ลু & $\stackrel{\infty}{ \pm}$ & 岁 & वे \\
\hline & & 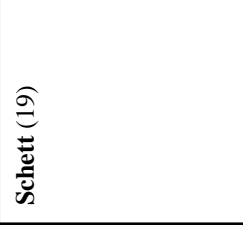 & 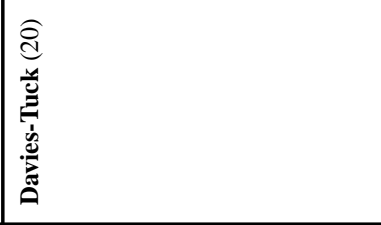 & 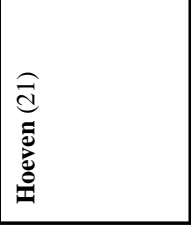 & 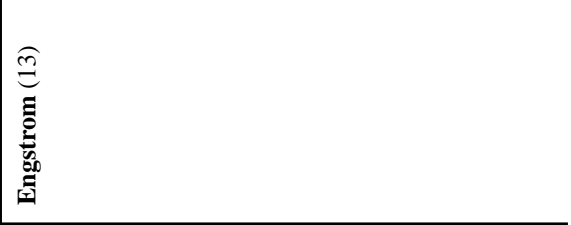 \\
\hline
\end{tabular}




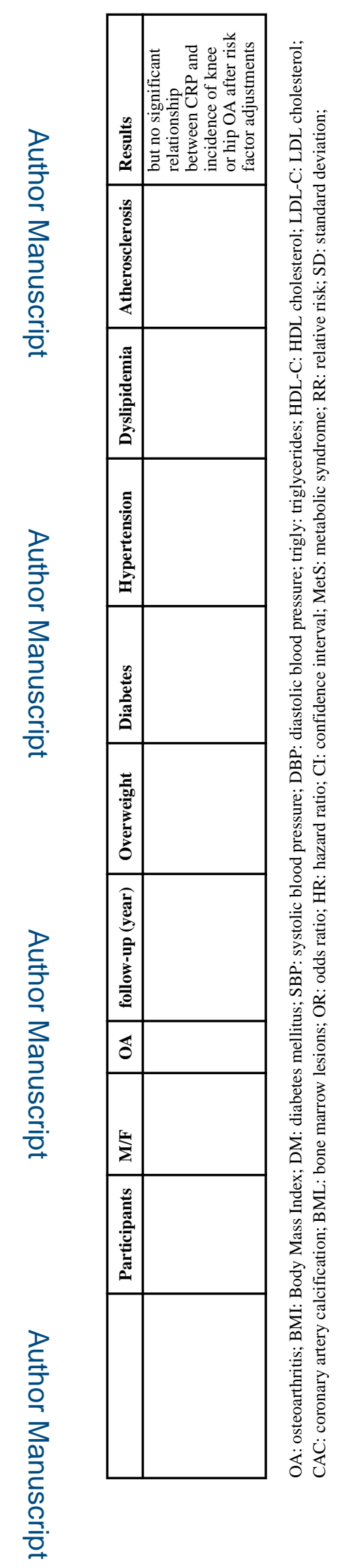

Arthritis Rheumatol. Author manuscript; available in PMC 2018 January 01. 


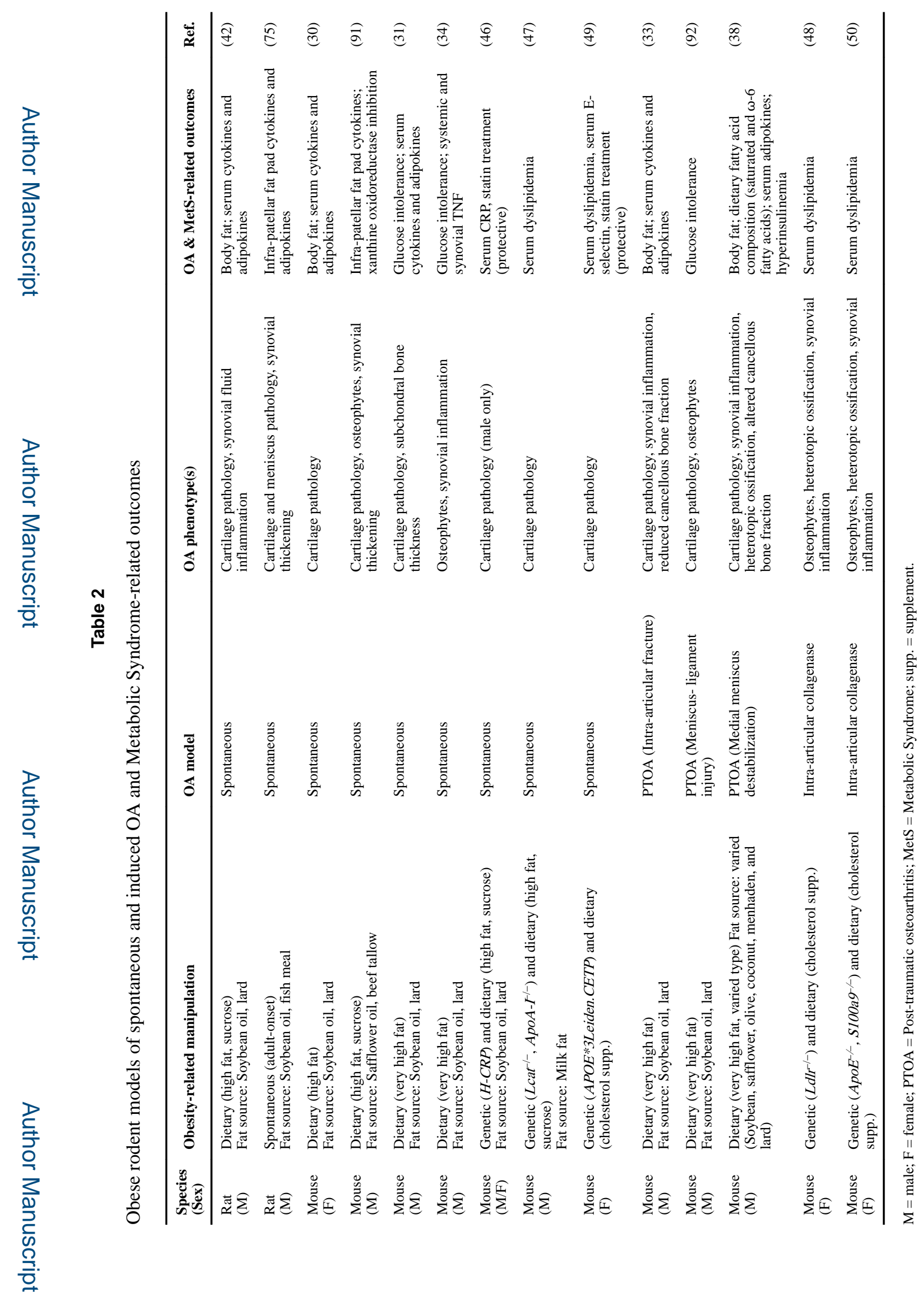

Arthritis Rheumatol. Author manuscript; available in PMC 2018 January 01. 